University of Nebraska - Lincoln

DigitalCommons@University of Nebraska - Lincoln

Faculty Publications: Department of

Entomology

Entomology, Department of

2020

\title{
Enhanced metabolism and selection of pyrethroid-resistant western corn rootworms (Diabrotica virgifera virgifera LeConte)
}

\author{
Dariane Souza \\ University of Nebraska-Lincoln, dariane.souza@ufl.edu \\ Arnubio V. Jiménez \\ Universidad de Caldas \\ Gautam Sarath \\ USDA-ARS, Wheat, Sorghum, and Forage Research Unit, Gautam.sarath@ars.usda.gov \\ Lance J. Meinke \\ University of Nebraska-Lincoln, Imeinke1@unl.edu \\ Nicholas J. Miller \\ Illinois Institute of Technology, nmiller11@iit.edu
}

See next page for additional authors

Follow this and additional works at: https://digitalcommons.unl.edu/entomologyfacpub

Part of the Entomology Commons

Souza, Dariane; Jiménez, Arnubio V.; Sarath, Gautam; Meinke, Lance J.; Miller, Nicholas J.; and Siegfried, Blair D., "Enhanced metabolism and selection of pyrethroid-resistant western corn rootworms (Diabrotica virgifera virgifera LeConte)" (2020). Faculty Publications: Department of Entomology. 868.

https://digitalcommons.unl.edu/entomologyfacpub/868

This Article is brought to you for free and open access by the Entomology, Department of at DigitalCommons@University of Nebraska - Lincoln. It has been accepted for inclusion in Faculty Publications: Department of Entomology by an authorized administrator of DigitalCommons@University of Nebraska - Lincoln. 


\section{Authors}

Dariane Souza, Arnubio V. Jiménez, Gautam Sarath, Lance J. Meinke, Nicholas J. Miller, and Blair D. Siegfried 


\title{
Enhanced metabolism and selection of pyrethroid-resistant western corn rootworms (Diabrotica virgifera virgifera LeConte)
}

\author{
Dariane Souza $^{\mathrm{a}, *}$, Arnubio V. Jiménez ${ }^{\mathrm{b}}$, Gautam Sarath ${ }^{\mathrm{c}}$, Lance J. Meinke ${ }^{\mathrm{a}}$, Nicholas J. Miller ${ }^{\mathrm{d}}$, \\ Blair D. Siegfried ${ }^{\mathrm{e}}$ \\ ${ }^{a}$ University of Nebraska-Lincoln, Department of Entomology, Lincoln 68583, United States of America \\ ${ }^{\mathrm{b}}$ Universidad de Caldas, Departamento de Producción Agropecuaria, Manizales, Colombia \\ ${ }^{\mathrm{c}}$ USDA-ARS, Wheat, Sorghum, and Forage Research Unit, Lincoln 68583, United States of America \\ ${ }^{\mathrm{d}}$ Illinois Institute of Technology, College of Science, Chicago 60616, United States of America \\ ${ }^{\mathrm{e}}$ University of Florida, Entomology and Nematology Department, Gainesville 32611, United States of America
}

\section{A R T I C L E I N F O}

\section{Keywords:}

Diabrotica virgifera virgifera

Western corn rootworm

Insecticide resistance

Pyrethroid resistance

Enzyme activity

\begin{abstract}
A B S T R A C T
Western corn rootworm (WCR) pyrethroid resistance has been previously reported in the United States (US) western Corn Belt, and cross-resistance and synergism studies suggested that both target site insensitivity and enhanced metabolism may be conferring WCR resistance to pyrethroids. The present study aimed to investigate the potential mechanisms of WCR pyrethroid resistance and to estimate the heritability of the resistance trait. Biochemical assays using model substrates and spectrophotometry revealed 2-4-fold higher activity of P450s and esterases in pyrethroid-resistant WCR populations, whereas the biological activity of glutathione $S$-transferase was similar between populations tested. No mutation in the voltage-gated sodium channel was detected in pyrethroid-resistant WCR individuals by sequencing PCR products containing the para-homologous L1014, T929, and M918 amino acid positions that are commonly associated with target site mutations in other pyrethroid-resistant insects. A pilot estimation of pyrethroid resistance heritability obtained during laboratory selection of a WCR population suggested a major genetic component of the resistance trait and predicted a 10-fold increase in WCR bifenthrin resistance within $\sim 7$ generations of insecticide lethal exposure. Results support earlier indirect evidence that enhanced metabolism may be contributing to WCR resistance to pyrethroids and illustrates the potential of WCR pyrethroid resistance evolution.
\end{abstract}

\section{Introduction}

Field-evolved resistance to pyrethroids has been confirmed among populations of the western corn rootworm (WCR), Diabrotica virgifera virgifera LeConte (Coleoptera: Chrysomelidae), in the western Corn Belt of the United States (US) (Pereira et al., 2015, 2017). Laboratory bioassays revealed WCR cross-resistance to pyrethroids and DDT (Pereira et al., 2017). A reduced performance of formulated pyrethroids that are aerially sprayed and soil-applied for WCR adult and larval control has also been confirmed (Souza et al., 2019a, 2019b). Treating field-collected pyrethroid-resistant WCR adults with insecticide synergists S,S,S-tributyl phosphorotrithioate (DEF) and piperonyl butoxide (PBO) prior to insecticide exposure partially reduced resistance to tefluthrin suggesting that both target-site insensitivity and insect enhanced metabolism could be components of the resistance mechanism
(Pereira et al., 2017).

Reduced adult susceptibility to the organophosphate dimethoate and increased susceptibility to the oxadiazine indoxacarb were also detected by active ingredient dose-response bioassays conducted on pyrethroid-resistant WCR populations (Souza et al., 2019b). Cross-resistance between structurally related insecticides such as pyrethroids and organophosphates is often associated with increased activity of detoxification enzymes such as cytochrome P450-dependent monooxygenases (P450s), esterases and glutathione $S$-transferases (Cahill et al., 1995; Carvalho et al., 2013; Chigure et al., 2018; Hemingway et al., 1993). Biological activity of esterase/amidases could be particularly important in hydrolyzing amide-containing insecticides such as dimethoate, and also in bioactivation of the pro-insecticide indoxacarb (Wing et al., 2000; Yu and Nguyen, 1998).

Non-synonymous nucleotide substitutions in the voltage-gated

\footnotetext{
*Corresponding author at: University of Florida, Entomology and Nematology Department, 1881 Natural Area Drive, Bldg. 970, Gainesville, FL 32611, United States of America

E-mail address: dariane.souza@ufl.edu (D. Souza).
} 
sodium channel gene can also provide resistance to insecticides that act as sodium channel modulators such as pyrethroids and DDT (Soderlund and Knipple, 2003). More than 50 sodium channel mutation combinations were reported to provide resistance to pyrethroids in various arthropod pests (Dong et al., 2014), which we referred to throughout this manuscript according to their amino acid position in the sodium channel protein sequence of house fly Musca domestica L. (Vssc1) deposited in GenBank (Acession No: AAB47604). Mutations at amino acid positions L1014 and T929 are the most common in conferring knockdown resistance $(k d r)$ to pyrethroids in different insect species and also in providing variable levels of cross-resistance between not only Type I and Type II pyrethroids, but also between pyrethroids and DDT (Burton et al., 2011; Dong et al., 2014; Usherwood et al., 2007). In another chrysomelid, the Colorado potato beetle Leptinotarsa decemlineata (Say), mutations at both L1014 and T929 were identified as a major mechanism of pyrethroid resistance (Rinkevich et al., 2012). Mutations at site M918 have also been shown to confer high levels of $k d r$ resistance in a number of different insect species (Dong et al., 2014; Williamson et al., 1993, 1996). The cross-resistance between the two classes of pyrethroids and DDT previously observed in pyrethroid-resistant WCR populations suggests that $k d r$ mutations may also be involved in the resistance mechanism (Pereira et al., 2017; Souza et al., 2019a, 2019b).

Although laboratory and field studies that have documented some practical implications of the WCR pyrethroid resistance trait, the mechanisms of resistance remain unknown. Laboratory selection experiments have been widely used to investigate insecticide resistance mechanisms and to examine the evolution of resistance traits under controlled conditions (Roush and McKenzie, 1987) assisting the characterization of WCR pyrethroid resistance. The selection process may act to increase the frequency of resistance-associated genes over time and provide a more homogeneous genetic background for study (Georghiou, 1972; Georghiou and Taylor, 1977). Furthermore, the realized heritability of resistance $\left(h^{2}\right)$ can be estimated during the process of selection (Falconer, 1989; Tabashnik, 1992), which allows the estimation of the resistance development rate that is critically important to resistance evolution modelling and insect resistance management (IRM) planning (Georghiou and Taylor, 1977; Oswald et al., 2011; Tabashnik, 1992).

The characterization of WCR pyrethroid resistance is important to IRM and Integrated Pest Management (IPM) throughout US maize producing areas. Biochemical and genetic studies would greatly contribute to the understanding of mechanisms involved in WCR pyrethroid resistance, complement the laboratory and field data collected thus far (Pereira et al., 2015, 2017; Souza et al., 2019a, 2019b) and potentially improve current resistance detection methods. Therefore, the objectives of this study were: (1) to select a pyrethroid-resistant WCR population in the laboratory and obtain a preliminary estimate of the realized heritability of the resistance trait; (2) screen pyrethroidresistant WCR populations for voltage-gated sodium channel sites that commonly harbor $k d r$ mutations in other insect species; and (3) evaluate the enzyme activity of pyrethroid-resistant WCR populations.

\section{Material and methods}

\subsection{Chemicals}

Bifenthrin analytical standard was purchased from Chem Service Inc. (West Chester, PA, Cat. No. N-11203-100MG/CAS: 82657-04-3). DNAzol $^{\circledR}$ reagent was obtained from Invitrogen (Carlsbad, CA, Cat No. 10503027). PolyAcryl Carrier was provided by Molecular Research Center Inc. (Cincinnati, OH, Cat No. PC152) and RNase A by MACHEREY-NAGEL GmbH \& Co. KG (Düren, Germany, Cat No. 740505). Proteinase K and QIAquick PCR Purification Kit were purchased from Qiagen Inc. (Germantown, MD, Cat No. 19131 and 28104 respectively). GoTaq $^{\circledR}$ Flexi DNA polymerase kit was obtained from Promega (Madison, WI, Cat No. M8291). Triton ${ }^{\mathrm{TM}}$ X-100 and Pierce ${ }^{\mathrm{TM}}$ bicinchoninic acid (BCA) assay kit were provided by Thermo Scientific (Rockford, IL, Cat No. 85112 and 23227 respectively). The Native Sample Buffer (161-0738) and $10 \times$ Tris Glycine/SDS buffer (161-0732) were purchased from Bio-Rad Laboratories (Hercules, CA). SigmaAldrich Corp. (St. Louis, MO) provided all PCR primers and remaining chemicals used including: reduced L-glutathione (G4251-5G/CAS: 7018-8); 1-chloro-2,4-dinitrobenzene (237329-10G/CAS: 97-00-7); p-nitroanisole (103543-5G/CAS: 100-17-4); p-nitrophenyl acetate (N81305G/CAS: 830-03-5); $\alpha$-naphthyl acetate (N8505/CAS: 830-81-9); $\beta$ naphthyl acetate (N6875/CAS: 1523-11-1); D-glucose 6-phosphate sodium salt (G7879-1G/CAS: 54010-71-8); NADP disodium salt (NADPRO/CAS: 24292-60-2); glucose-6-phosphate dehydrogenase (G6378500UN/CAS: 9001-40-5); and fast Blue RR salt (F0500/CAS: 14726-29$5)$.

\subsection{Screening for WCR kdr mutations}

Three WCR populations showing 5-15-fold resistance to bifenthrin were screened for para-homologous $k d r$ mutations in the voltage-gated sodium channel gene. Two were collected from cornfields $\sim 14 \mathrm{~km}$ apart in Keith County, NE (R-Field1 and R-Field3) in 2015 and 2016, respectively. The third population (R-Lab) was collected from Perkins County, NE in 2014 and then reared in a non-diapause background for four generations under adult bifenthrin selection (subsection 2.4).

To confirm resistant individuals within each resistant population, mixed-age WCR beetles were transferred to glass vials coated with a pre-established bifenthrin diagnostic concentration $(0.77 \mu \mathrm{g}$ of bifenthrin/vial) corresponding to a pooled $\mathrm{LC}_{99}$ of pyrethroid-susceptible WCR populations (Pereira et al., 2015). After $24 \mathrm{~h}$ of insecticide exposure, surviving beetles were flash frozen in liquid nitrogen and stored at $-80{ }^{\circ} \mathrm{C}$. WCR beetles purchased from Crop Characteristics Inc., Farmington, MN (S-Lab1) were used as pyrethroid-susceptible controls.

Genomic DNA was extracted from six WCR beetles (1:1 sex ratio) from each population using DNAzol ${ }^{\circledR}$ reagent according to the manufacturer's instructions with the following modifications for tissue homogenization and lysis. WCR abdomens were removed with micro scissors and remaining body parts were placed in $1.5 \mathrm{~mL}$ tubes. Each sample was homogenized with disposable microtube pestles in $980 \mu \mathrm{L}$ of DNAzol and $10 \mu \mathrm{L}$ of PolyAcryl carrier. Homogenates were treated with $10 \mu \mathrm{L}$ of RNase A and placed in a thermomixer (Thermomixer 5350 Mixer, Eppendorf AG, Hamburg, Germany) at $37{ }^{\circ} \mathrm{C}$. After $1 \mathrm{~h}$, each sample received $8 \mu \mathrm{L}$ of proteinase $\mathrm{K}$ and was incubated at $55{ }^{\circ} \mathrm{C}$ for one hour in the thermomixer. Tubes with the resulting mixture were then left on the laboratory bench for $3 \mathrm{~h}$ at room temperature and processed for DNA isolation as recommended by the manufacturer.

Polymerase chain reactions (PCR) were performed in a $50 \mu \mathrm{L}$ final reaction volume containing $100 \mathrm{ng}$ of template DNA, $1 \mathrm{u}$ of $\mathrm{GoTaq}^{\circledR}$ Flexi DNA polymerase, $1 \times$ Colorless GoTaq ${ }^{\circledR}$ Flexi buffer, $0.2 \mathrm{mM}$ dNTP, $1.5 \mathrm{mM} \mathrm{MgCl}_{2}$ and $0.2 \mu \mathrm{M}$ of each primer. The PCR temperature profile for each fragment included an initial heating step at $95{ }^{\circ} \mathrm{C}$ for $2 \mathrm{~min}$, followed by 35 cycles of $94{ }^{\circ} \mathrm{C}$ for $30 \mathrm{~s}$, annealing temperature for $90 \mathrm{~s}$ and $72{ }^{\circ} \mathrm{C}$ for $1 \mathrm{~min}$, and a final extension of $60{ }^{\circ} \mathrm{C}$ for $30 \mathrm{~min}$. The forward (5'-GGTTTTCAGATAATGTAGATAG-3') and reverse (5'TTCCCAACCACCACATTTTT- $3^{\prime}$ ) primers were used with an annealing temperature of $54{ }^{\circ} \mathrm{C}$ to amplify a $\sim 350$ bp region near the $k d r$ locus homologous to L1014 in Vssc1. Also, forward (5'-ATGGAGGCATGTTG TCGAGA-3') and reverse (5'-GCCACGAAAGACCGAAAGAA-3') primers were used with an annealing temperature of $65^{\circ} \mathrm{C}$ to amplify a $\sim 530 \mathrm{bp}$ region containing $k d r$ loci homologous to M918 and T929 in Vssc1. Primers were designed using Primer3web version 4.0.0 (Koressaar and Remm, 2007; Untergasser et al., 2012) and a draft WCR genome as template (Hugh Robertson, University of Illinois, personal communication).

To locate the $k d r$ polymorphic sites, sequences extracted from a WCR genome were aligned to the sodium channel sequence of housefly M. domestica L. (Vssc1) deposited in GenBank (Acession No: 
AAB47604). DNA concentration and quality were determined by spectrophotometry using the Nanodrop 2000 (Thermo Scientific ${ }^{\mathrm{TM}}$, Waltham, MA) and by visualization in 1.3\% agarose gel electrophoresis. PCR products were purified with QIAquick PCR Purification Kit and sequenced at the University of Nebraska Medical Center (UNMC, Omaha, NE) with an Applied Biosystems (ABI) 3730 DNA Analysis Instrument (Life Technologies, Grand Island, NY). Reads were quality trimmed with pregap4 v1.6-r and assembled by gap4 v4.11.2-r. The consensus sequences were aligned and mapped to a scaffold of the WCR sodium channel gene using Geneious Basic 5.6.7 (Auckland, New Zealand) (Kearse et al., 2012), and screened for targeted $k d r$ polymorphisms.

\subsection{Enzyme activity of pyrethroid-resistant WCR populations}

\subsubsection{Enzyme preparation}

In 2017, the activity of P450s, esterases and glutathione S-transferases were compared among five WCR adult populations using model substrate assays. Three pyrethroid-resistant populations were collected from cornfields in Keith Co., NE that were 8-14 km apart from each other (R-Field1, R-Field2 and R-Field3). Another population was the ninth generation of the R-Lab population selected for bifenthrin resistance (subsection 2.4). A population collected from Saunders Co., NE (S-Field) was included as a pyrethroid-susceptible control. All field populations were collected in 2016 and reared in the laboratory for one generation prior to testing under the same conditions and standard rearing procedure (Wangila et al., 2015). Pyrethroid susceptibility levels of the WCR populations tested had been previously determined (Pereira et al., 2015, 2017; Souza et al., 2019a, 2019b).

Two experiments were performed with three biological replicates. Each biological replicate consisted of ten WCR adults (48 h-old and 1:1 sex ratio) pooled together. Whole body preparations were used in the first experiment whereas only WCR abdomens were used in the second. Each replicate was homogenized on ice with a Polytron homogenizer (Brinkmann Instruments, Westbury, NY) in a Teflon glass PotterElvehjem-type tube with $1.3 \mathrm{~mL}$ of ice-cold $0.1 \mathrm{M}$ Tris-HCl homogenization buffer ( $\mathrm{pH} 7.8$ ) containing $10 \mathrm{mM} \mathrm{MgCl}_{2}, 100 \mathrm{mM} \mathrm{NaCl}_{2}$, $0.1 \mathrm{mM}$ dithiothreitol, $1 \mathrm{mM}$ phenylthiourea and $10 \% \mathrm{v} / \mathrm{v}$ glycerol. The homogenates were transferred into $1.5 \mathrm{~mL}$ tubes and centrifuged for $20 \mathrm{~min}$ at $4{ }^{\circ} \mathrm{C}$ and $10,000 \times \mathrm{g}$. Supernatants were then transferred into new $1.5 \mathrm{~mL}$ tubes. An aliquot of $40 \mu \mathrm{L}$ from each enzyme preparation was diluted 5-fold in $0.1 \mathrm{M}$ Tris- $\mathrm{HCl}$ homogenization buffer for both enzyme activity measurement and protein quantification. Protein concentration for all preparations was determined with Pierce ${ }^{\mathrm{TM}}$ BCA assay kit following manufacturer's instructions and using bovine serum albumin standards.

\subsubsection{Enzyme assays}

Activities of P450-dependent demethylation, esterase and glutathione S-transferase were measured (30s intervals) using a microplate spectrophotometer reader (PowerWave ${ }^{\mathrm{TM}} \mathrm{HT}$, BioTek ${ }^{\circledR}$ Instruments, Inc., Winooski, VT) and model substrates in 96-well sterile plates (Corning ${ }^{\circledR}$ Costar ${ }^{\circledR}$, Corning, NY, Cat No. CLS3595). Protocols were adapted from methods developed previously (Rose et al., 1995; Yang et al., 2004). The P450 substrate solution was prepared using the homogenization buffer to a final concentration of $2 \mathrm{mM}$ p-nitroanisole and $0.05 \mathrm{M}$ Tris$\mathrm{HCl}$. Reaction mixtures contained $90 \mu \mathrm{L}$ of non-diluted enzyme preparation $(610 \mu \mathrm{g} / \mu \mathrm{L})$ and $100 \mu \mathrm{L}$ of substrate solution per well. The reaction was initiated by the addition of $10 \mu \mathrm{L}$ of a NADPH regenerating system $\left(0.25 \mathrm{mM} \mathrm{NADP}{ }^{+}, 2.5 \mathrm{mM}\right.$ D-Glucose 6-phosphate, $1 \mathrm{u}$ of glucose-6-phosphate dehydrogenase) after a $3 \mathrm{~min}$ incubation period at $30{ }^{\circ} \mathrm{C}$. The absorbance of product $p$-nitrophenol was read at $405 \mathrm{~nm}$ and $30{ }^{\circ} \mathrm{C}$ for $15 \mathrm{~min}$. For the esterase assays, $10 \mu \mathrm{L}$ of the 5 -fold diluted enzyme $(122 \mu \mathrm{g} / \mu \mathrm{L})$ and $190 \mu \mathrm{L}$ of substrate solution $(5.26 \mathrm{mM} p$-nitrophenyl acetate, $0.05 \mathrm{M}$ Tris- $\mathrm{HCl}$ ) were added to each well and $p$ nitrophenol absorbance was read at $405 \mathrm{~nm}$ and $30{ }^{\circ} \mathrm{C}$ for $4 \mathrm{~min}$. Both
P450 O-demethylation and esterase activities were determined using the extinction coefficient of $18 \mathrm{mM}^{-1} \mathrm{~cm}^{-1}$. Glutathione S-transferase substrate solution was prepared with the homogenization buffer adjusted to a pH 7.4 and a final concentration of $1.3 \mathrm{mM} \mathrm{1-chloro-2,4-}$ dinitrobenzene, $6 \mathrm{mM}$ reduced glutathione, and $0.05 \mathrm{M}$ Tris-HCl. Individual wells of the microtiter plate received $10 \mu \mathrm{L}$ of diluted enzyme $(122 \mu \mathrm{g} / \mu \mathrm{L})$ and $190 \mu \mathrm{L}$ of substrate solution. The absorbance of $S$ - $(2,4-$ dinitrophenyl) glutathione was measured at $340 \mathrm{~nm}, 30{ }^{\circ} \mathrm{C}$ during $15 \mathrm{~min}$, and the activity of glutathione $S$-transferase calculated using the extinction coefficient of $9.6 \mathrm{mM}^{-1} \mathrm{~cm}^{-1}$. Three technical replicates were used in all microplate assays for each of the three biological replicate enzyme preparations (subsection 2.3.1). Enzyme activities were subjected to analysis of variance using a completely randomized experimental design followed by Fisher's least significant difference procedure for comparison of treatment means at significance level $\alpha=0.1$.

\subsubsection{In-gel esterase activity}

The 5-fold diluted homogenates freshly prepared from WCR whole bodies were also used for in-gel esterase activity assays adapted from Wright et al. (2000) and Thangthaeng et al. (2011). Sodium dodecyl sulfate-polyacrylamide gel electrophoresis (SDS-PAGE) was performed in a vertical electrophoresis chamber (Bio-Rad Protean II, Richmond, CA) using 4-15\% Mini-PROTEAN TGX Precast Gel (Bio-Rad Laboratories, Hercules, CA, Cat No. 4561086) and $1 \times$ Tris Glycine/SDS buffer (25 mM Tris, $192 \mathrm{mM}$ glycine, 0.1\% SDS). Individual wells were loaded with $20 \mu \mathrm{L}$ of solution containing $10 \mu \mathrm{g}$ of total protein, $6 \% \nu / \mathrm{v}$ sucrose and $3 \mu \mathrm{L}$ of Bio-Rad native sample buffer. Gels were run at $4{ }^{\circ} \mathrm{C}, 90 \mathrm{~V}$ for $15 \mathrm{~min}$ and then at $110 \mathrm{~V}$ for $1 \mathrm{~h}$. Following SDS-PAGE, gels were incubated at room temperature for $30 \mathrm{~min}$ in $3 \%$ Triton $^{\mathrm{TM}} \mathrm{X}-100$ solution, rinsed with ultrapure water and then incubated at $40{ }^{\circ} \mathrm{C}$ for $20 \mathrm{~min}$ in $100 \mathrm{~mL}$ staining solution of $50 \mathrm{mM}$ Tris- $\mathrm{HCl}(\mathrm{pH} 7.4)$ containing $50 \mathrm{mg}$ $\alpha$ - or $\beta$-naphthyl acetate dissolved in $1 \mathrm{~mL}$ ethanol, and $50 \mathrm{mg}$ of solid Fast blue RR salt. Upon development of visible bands, gels were briefly rinsed with ultrapure water and the reaction stopped by fixing the gel in a solution of $50 \% \mathrm{v} / \mathrm{v}$ methanol and $10 \% \mathrm{v} / \mathrm{v}$ acetic acid. Gel images were analyzed using the ImageJ 1.52a program (NIH, Bethesda, MO), which generated a profile of band intensity for each lane of the gel allowing both qualitative and quantitative measurements of activity (Schneider et al., 2012).

\subsection{Realized heritability of WCR bifenthrin resistance}

In the summer of 2014, 500 WCR adult males collected in Perkins County, NE and confirmed to be pyrethroid-resistant (Pereira et al., 2015) were mated with 500 non-diapausing WCR virgin females purchased from Crop Characteristics, Inc., Farmington, MN that were previously shown to be susceptible to pyrethroids (Pereira et al., 2015, 2017; Souza et al., 2019a, 2019b). The mating was performed to obtain non-diapausing WCR offspring (R-Lab) that would carry alleles conferring pyrethroid resistance and serve as a base population for laboratory selection. Non-diapausing females were chosen for the mating because it has been reported that the diapause characteristic is a maternally inherited trait (Branson, 1976; Krysan, 1978; Krysan et al., 1977).

The resulting population (R-Lab) was maintained under continuous rearing conditions (Wangila et al., 2015) in the Department of Entomology of the University of Nebraska-Lincoln. The second, fourth, sixth and seventh adult generations were selected for pyrethroid resistance by exposure to glass scintillation vials (Wheaton ${ }^{\mathrm{TM}}$, Thermo Fisher Scientific Inc., Waltham, MA, Cat. No. 03-340-25N) treated with a pre-established bifenthrin diagnostic concentration ( $\mathrm{LC}_{99}$ ) (Pereira et al., 2015). Vials were also treated with increasing bifenthrin concentrations to perform concentration-response bioassays and estimate the susceptibility of the fourth and eighth R-Lab adult generations. An analytical standard of bifenthrin diluted in acetone was used in all treatments and controls consisted of acetone-only treated vials. 
Sodium-channel $k d r$ polymorphic sites ${ }^{a}$

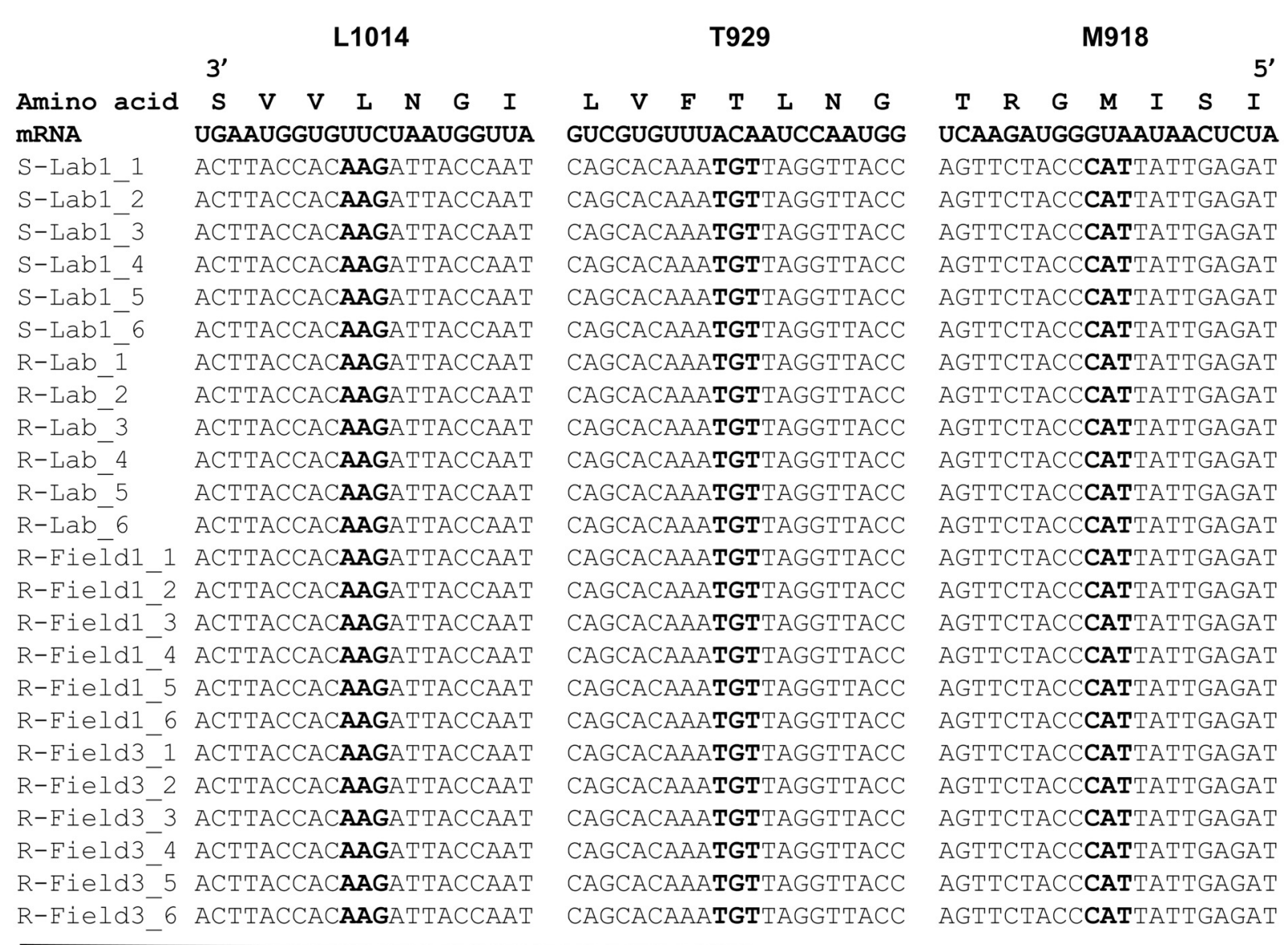

akdr sites are numbered according to the amino acid sequence of Vssc1 deposited in GenBank (Accession No: AAB47604)

Fig. 1. Screening of pyrethroid-resistant (R-) and pyrethroid-susceptible (S-) WCR populations for $k d r$ mutations. Figure shows partial DNA-seq alignment of PCR product sequences amplifying three para-homologous $k d r$ loci (L1014, T929, and M918).

Ten unsexed WCR adults were individually transferred to treated vials at $48 \mathrm{~h}$ post-emergence and before mating. All treatments were maintained at a temperature of $23 \pm 1{ }^{\circ} \mathrm{C}$ and $13 \pm 1 \mathrm{~h}$ light period and mortality was recorded after $24 \mathrm{~h}$ of exposure. Insects that did not respond to prodding or were unable to walk consistently when placed ventral side down were considered dead. WCR adults surviving the $\mathrm{LC}_{99}$ of bifenthrin were maintained under the same lab rearing procedure. Mortality data collected from the fourth and eight generation of R-Lab concentration-response bioassays were analyzed by Probit analysis in POLOPlus-PC LeOra Software LLC (Finney, 1971; LeOra, 1987; Russell and Robertson, 1979). Slopes and $\mathrm{LC}_{50}$ values were used to calculate the realized heritability of bifenthrin resistance $\left(h^{2}\right)$ and the number of generations required for a 10 -fold increase in $\mathrm{LC}_{50}(G)$ following methods previously described (Tabashnik, 1992).

\section{Results}

\subsection{Screening for WCR kdr mutations}

WCR populations were screened for L1014, T929, and M918 $k d r$ para-homologous mutations in the voltage-gated sodium channel gene (Fig. 1). However, relative to the pyrethroid-susceptible population SLab1, no mutations were found for the targeted loci in any of the 18 individuals originated from pyrethroid-resistant WCR populations (RLab, R-Field1, and R-Field3) that survived a bifenthrin diagnostic concentration ( $\left.\mathrm{LC}_{99}\right)$.

\subsection{Enzyme activity of pyrethroid-resistant WCR populations}

Significant enzyme activity differences were observed in WCR populations (Fig. 2). All pyrethroid-resistant WCR populations tested (RField1, R-Field2, R-Field3, and R-Lab) exhibited a significantly higher activity of P450-dependent $O$-demethylation (2-4-fold) relative to the pyrethroid-susceptible population S-Field (Fig. 2A). The $O$-demethylation level was higher in field-derived populations R-Field2, R-Field3 than in the lab-derived resistant population R-Lab (Fig. 2A).

Relative to pyrethroid-susceptible S-Field, esterase activity of whole-body homogenates using $p$-nitrophenyl acetate as substrate was also significantly higher (2-3-fold) in pyrethroid-resistant WCR field populations R-Field1, R-Field2 and R-Field3 (Fig. 2B). In contrast, esterase activity of the R-Lab was not statistically different from the susceptible WCR population S-Field (Fig. 2B). The whole-body esterase activity pattern observed for the WCR populations tested (Fig. 2B) was consistently similar to that observed with WCR abdomens (Fig. 2C). Activity of glutathione S-transferases in whole-body homogenates towards 1-chloro 2,4-dinitrobenzene was not significantly different among WCR populations (Fig. 2D).

The in-gel esterase activity towards $\alpha$-/ $\beta$-naphthyl acetate substrates (Fig. 3) did not show strong differences among WCR populations in contrast to the microplate assays with $p$-nitrophenyl acetate substrate 

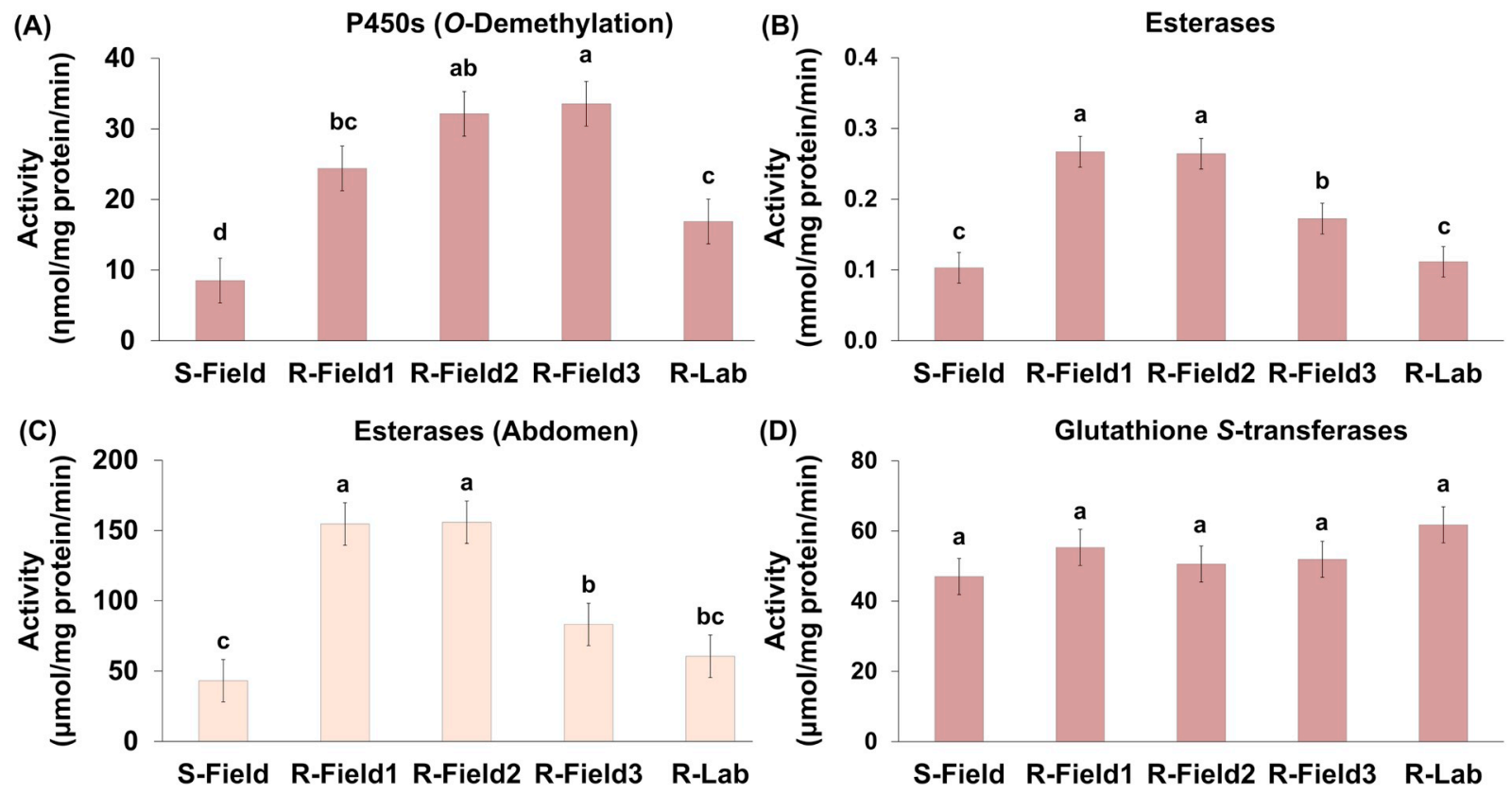

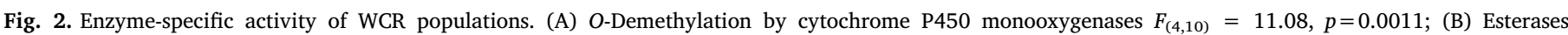

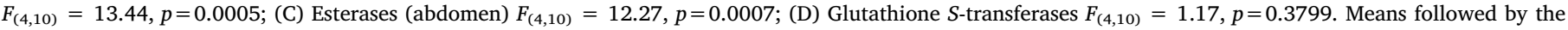
same letter were not statistically different at the significance level $\alpha=0.1$.

(A)

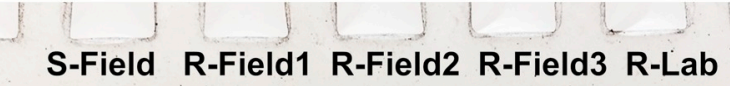

1

2

3

4

(C)

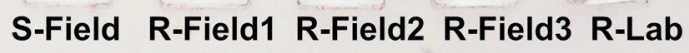

(B)

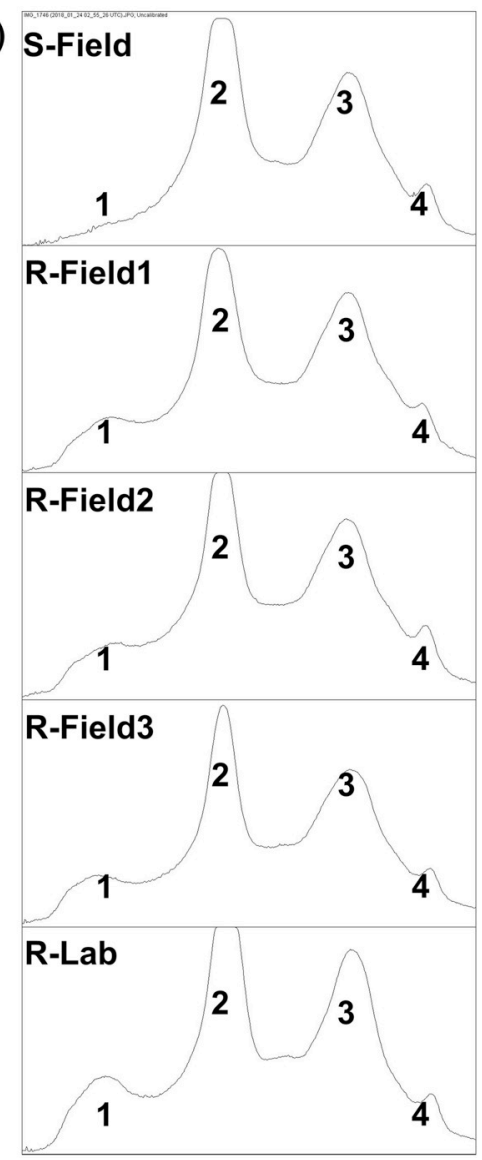

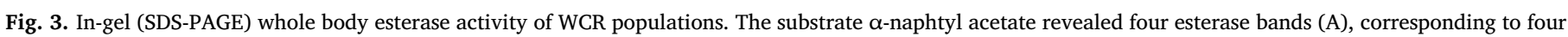

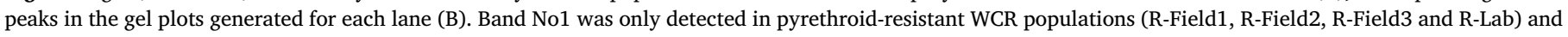
not in the -susceptible WCR population (S-Field). Gels using $\beta$-naphtyl acetate substrate (C) were not as clear as gels using the $\alpha$-isomer. 
Table 1

Estimation of bifenthrin resistance realized heritability $\left(h^{2}\right)$ in a laboratory selected WCR population.

\begin{tabular}{|c|c|c|c|c|c|c|c|c|c|c|}
\hline \multirow[t]{2}{*}{ No. of generations selected $(n)$} & \multicolumn{3}{|c|}{ Mean selection response per generation } & \multicolumn{6}{|c|}{ Mean selection differential per generation } & \multirow[t]{2}{*}{$h^{2}$} \\
\hline & Initial $\log \mathrm{LC}_{50}$ & Final $\log \mathrm{LC}_{50}$ & $R$ & $p$ & $i$ & Initial slope & Final slope & $\left(\sigma_{p}\right)$ & $S$ & \\
\hline 3 & 0.01 & 0.44 & 0.14 & 57.92 & 0.61 & 3.33 & 1.58 & 0.41 & 0.25 & 0.58 \\
\hline
\end{tabular}

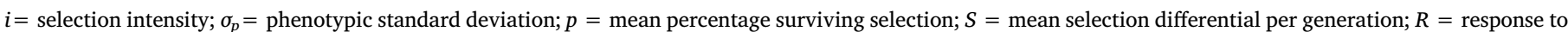
selection.

(Fig. 2). However, $\alpha$-naphthyl acetate revealed at least four esterase bands (Fig. 3A) corresponding to four peaks in the gel plots generated (Fig. 3B), one of which (band No 1) was only evident in the pyrethroidresistant WCR populations. Relative to the susceptible WCR population S-Field, band No 1 was stronger in R-Lab ( $\sim 440$-fold) than in the pyrethroid-resistant WCR field populations R-Field1 ( $\sim 207$-fold), R-Field2 ( $\sim 168$-fold), and R-Field3 ( $\sim 216$-fold). The $\alpha$-naphthyl acetate (Fig. $3 \mathrm{~A})$ provided better visualization of esterase activity than the $\beta$ isomer (Fig. 3C).

\subsection{Realized heritability of WCR bifenthrin resistance}

The laboratory selection experiment of WCR bifenthrin resistance provided an estimate of realized heritability $\left(h^{2}\right)$ (Table 1$)$. For a 0.61 selection intensity $(i)$ with a phenotypic standard deviation $\left(\sigma_{p}\right)$ of 0.41 , the mean percentage surviving selection $(p)$ was 57.92 and mean selection differential per generation $(S)$ was 0.25 . Based on three generations of laboratory selection and a 0.14 response to selection $(R)$, the estimated $h^{2}$ of R-Lab bifenthrin resistance was 0.58 . The number of generations required for a 10 -fold increase in bifenthrin $\mathrm{LC}_{50}(G)$ was estimated to be 6.7 .

\section{Discussion}

Field evolved WCR pyrethroid-resistance was first identified in 2014, but the mechanism(s) of the resistance are still unclear (Pereira et al., 2015, 2017; Souza et al., 2019a, 2019b). Although cross-resistance to DDT found in pyrethroid-resistant WCR populations suggested that target-site insensitivity may be a contributing factor (Pereira et al., 2017), no mutations were detected among previously identified locations associated with $k d r$ resistance in another chrysomelid beetle (Colorado potato beetle) as well as in other insect species (Dong et al., 2014; Rinkevich et al., 2012). Sequencing of PCR products that could possibly contain the putative $k d r$ mutations indicated an absence of mutations in pyrethroid-resistant WCR individuals. If target-site insensitivity were associated with the WCR pyrethroid-resistance, it could represent a novel mutation not previously identified within Chrysomelidae.

Insecticide synergism observed in pyrethroid-resistant WCR populations treated with enzyme inhibitors and their relative susceptibility to dimethoate and indoxacarb suggested that enhanced metabolism could be contributing to WCR pyrethroid resistance (Pereira et al., 2017; Souza et al., 2019b), and our study confirmed higher P450 and esterase activity in pyrethroid-resistant WCR populations. The fact that P450-dependent demethylation and esterase activity observed in the laboratory selected WCR population (R-Lab) were not as high as in pyrethroid-resistant field populations may indicate that some P450 and esterase alleles were lost during introgression into a non-diapause background and the selection process resulting in a change of genes selected relative to the field resistant populations. In studies that examined differences between lab-selected and field-derived DDT-resistant Drosophila populations that over-transcribed Cyp6g1, researchers found that continuous laboratory selection can co-select other P450 genes (Brandt et al., 2002; Seong et al., 2017). Furthermore, if the original allele is removed from the population by population crosses and backcrosses prior to selection, different P450 genes may be selected (Le Goff et al., 2003). Differences in expression of P450 genes were also observed in other insect species when comparing lab-selected and fieldderived pyrethroid-resistant populations (Yang et al., 2006), including up- and down-regulation of P450 genes (Yang and Liu, 2011).

It is also possible that isoenzymes with less specificity for the substrates used in the microplate assays could have been selected in the RLab populations. For example, conflicting results when using $p$-nitrophenyl acetate and $\alpha-/ \beta$-naphthyl acetate substrates to measure esterase activity were reported previously (Montella et al., 2007). Results from the in-gel enzyme activity assay performed with $\alpha$-naphthyl acetate suggest that an esterase isozyme may be present only in pyrethroid-resistant WCR populations, and more active in the laboratory selected population R-Lab. Multi-gene enzyme families such as P450s and esterases exist in living organisms with differing specificities. Discriminating between these enzymes in assays using model substrates may not be possible and alternatives that more closely mimic endogenous substrates may be necessary. Complementary molecular investigation that identifies specific mutations or changes in gene regulation and expression could also provide further clarification (ffrenchConstant et al., 2004; Montella et al., 2012; Stitt and Gibon, 2014). Application of antibody techniques (e.g. ELISA) and more complex enzyme kinetic analyses providing functional information about proteins (e.g. $k_{\text {cat }}, K_{\mathrm{m}}$ and $V_{\max }$ values) could be further used to determine if differences in enzyme activity were due to properties of the enzyme itself or if differing amounts of enzyme were produced by resistant populations (Schilder et al., 2011; Stitt and Gibon, 2014).

The laboratory selection of a non-diapausing pyrethroid-resistant WCR population and realized heritability $\left(h^{2}\right)$ estimation performed in this study was a pilot investigation that suggests phenotypic variance is primarily due to genetic factors, and that a substantial increase in WCR resistance should be expected after $\sim 7$ generations of insecticide exposure. The value of $h^{2}$ is not constant as it tends to decline once homozygotes are accumulated after selection and variation becomes fixed (Johnson, 1979). Also, the $h^{2}$ estimate does not necessarily apply to other WCR populations since heritability is a population parameter that depends on population specific factors such as allele frequencies under defined selection intensities (Falconer, 1989, Shi et al. 2015). The cross between a non-diapause susceptible and a field derived resistant WCR population likely resulted in a high initial frequency of resistant alleles in the selected population and the estimate of heritability is likely to have been inflated. A more rigorous study involving simultaneous selection of multiple WCR field populations could provide the estimation of errors and confidence intervals associated with the heritability parameter. However, the present $h^{2}$ estimated indicates a rapid WCR response to bifenthrin selection and provides evidence of the potential for WCR pyrethroid resistance evolution.

Based on the combined results of our investigation, we conclude that increased P450 and esterase activity in pyrethroid-resistant WCR may be part of the resistance mechanism. Additional work is needed to investigate other potential $k d r$ sites in the sodium channel gene of pyrethroid-resistant WCR and to also identify the P450s and esterases expressed differently in pyrethroid-resistant WCR populations. Our pilot analysis of WCR selection for resistance suggests that WCR has substantial potential for achieving increasing pyrethroid resistance 
levels in the field within a relatively short period of time. This emphasizes the importance of considering WCR resistance management strategies within IPM programs, especially in areas of the US western Corn Belt where WCR pyrethroid resistance was confirmed.

\section{Acknowledgements}

The authors would like to thank Dr. Ana Maria Vélez and Dr. Joe Louis (Entomology Department, University of Nebraska-Lincoln) for sharing their laboratory space and/or equipment for some of the experiments performed in this study.

\section{Funding}

This work was supported by the Brazilian Ministry of Education Foundation CAPES [grant number 013398/2013-00]; and Monsanto Company [Corn Rootworm Knowledge Grant number 69292].

\section{References}

Brandt, A., Scharf, M., Pedra, J.H.F., Holmes, G., Dean, A., Kreitman, M., Pittendrigh, B.R., 2002. Differential expression and induction of two Drosophila cytochrome P450 genes near the Rst(2)DDT locus. Insect Mol. Biol. 11, 337-341.

Branson, T.F., 1976. The selection of a non-diapause strain of Diabrotica Virgifera (Coleoptera: Chrysomelidae). Entomol. Exp. Appl. 19, 148-154. https://doi.org/10. 1111/j.1570-7458.1976.tb02591.x.

Burton, M.J., Mellor, I.R., Duce, I.R., Davies, T.G.E., Field, L.M., Williamson, M.S., 2011. Differential resistance of insect sodium channels with $k d r$ mutations to deltamethrin, permethrin and DDT. Insect Biochem. Mol. Biol. 41, 723-732. https://doi.org/10. 1016/j.ibmb.2011.05.004.

Cahill, M., Byrne, F.J., Gorman, K., Denholm, I., Devonshire, A.L., 1995. Pyrethroid and organophosphate resistance in the tobacco whitefly Bemisia tabaci (Homoptera: Aleyrodidae). Bull. Entomol. Res. 85, 181-187. https://doi.org/10.1017/ S0007485300034258.

Carvalho, R.A., Omoto, C., Field, L.M., Williamson, M.S., Bass, C., 2013. Investigating the molecular mechanisms of organophosphate and pyrethroid resistance in the fall armyworm Spodoptera frugiperda. PLoS One 8, e62268. https://doi.org/10.1371/ journal.pone.0062268.

Chigure, G.M., Sharma, A.K., Kumar, S., Fular, A., Sagar, S.V., Nagar, G., Upadhaya, D., Saravanan, B.C., Kumar, R., Ghosh, S., 2018. Role of metabolic enzymes in conferring resistance to synthetic pyrethroids, organophosphates, and phenylpyrazole compounds in Rhipicephalus microplus. Int. J. Acarol. 44, 28-34. https://doi.org/10.1080/ 01647954.2017.1400588.

Dong, K., Du, Y., Rinkevich, F., Nomura, Y., Xu, P., Wang, L., Silver, K., Zhorov, B.S., 2014. Molecular biology of insect sodium channels and pyrethroid resistance. Insect Biochem. Mol. Biol. 50, 1-17. https://doi.org/10.1016/j.ibmb.2014.03.012.

Falconer, D.S., 1989. Introduction to Quantitative Genetics, 3rd ed. Longman Scientific \& Technical, New York.

ffrench-Constant, R.H., Daborn, P.J., Goff, G.L., 2004. The genetics and genomics of insecticide resistance. Trends Genet. 20, 163-170. https://doi.org/10.1016/j.tig.2004. 01.003.

Finney, D.J., 1971. Probit Analysis, 3rd ed. Cambridge University Press, Cambridge.

Georghiou, G.P., 1972. The evolution of resistance to pesticides. Annu. Rev. Ecol. Syst. 3, 133-168. https://doi.org/10.1146/annurev.es.03.110172.001025.

Georghiou, G.P., Taylor, C.E., 1977. Genetic and biological influences in the evolution of insecticide resistance. J. Econ. Entomol. 70, 319-323. https://doi.org/10.1093/jee/ 70.3.319.

Hemingway, J., Dunbar, S.J., Monro, A.G., Small, G.J., 1993. Pyrethroid resistance in german cockroaches (Dictyoptera: Blattelidae): resistance levels and underlying mechanisms. J. Econ. Entomol. 86, 1931-1938. https://doi.org/10.1093/jee/86.6. 1931.

Johnson, C., 1979. An overview of selection theory and analysis. Quantitative Genetic Variation. Academic Press, New York, pp. 111-119.

Kearse, M., Moir, R., Wilson, A., Stones-Havas, S., Cheung, M., Sturrock, S., Buxton, S., Cooper, A., Markowitz, S., Duran, C., Thierer, T., Ashton, B., Meintjes, P., Drummond, A., 2012. Geneious basic: an integrated and extendable desktop software platform for the organization and analysis of sequence data. Bioinformatics 28, 1647-1649. https://doi.org/10.1093/bioinformatics/bts199.

Koressaar, T., Remm, M., 2007. Enhancements and modifications of primer design program Primer3. Bioinformatics 23, 1289-1291. https://doi.org/10.1093/ bioinformatics/btm091.

Krysan, J.L., 1978. Diapause, quiescence, and moisture in the egg of the western corn rootworm, Diabrotica virgifera. J. Insect Physiol. 24, 535-540. https://doi.org/10. 1016/0022-1910(78)90055-0.

Krysan, J.L., Branson, T.F., Castro, G.D., 1977. Diapause in Diabrotica virgifera (Coleoptera: Chrysomelidae): a comparison of eggs from temperate and subtropical climates. Entomol. Exp. Appl. 22, 81-89. https://doi.org/10.1111/j.1570-7458. 1977.tb02694.x.

Le Goff, G., Boundy, S., Daborn, P.J., Yen, J.L., Sofer, L., Lind, R., Sabourault, C., MadiRavazzi, L., ffrench-Constant, R.H., 2003. Microarray analysis of cytochrome P450 mediated insecticide resistance in Drosophila. Insect Biochem. Mol. Biol. 33, 701-708.

LeOra, 1987. Polo-PC: A user's Guide to Probit or Logit Analysis. LeOra Software, Berkeley.

Montella, I.R., Martins, A.J., Viana-Medeiros, P.F., Lima, J.B.P., Braga, I.A., Valle, D., 2007. Insecticide resistance mechanisms of Brazilian Aedes aegypti populations from 2001 to 2004. Am. J. Trop. Med. Hyg. 77, 467-477.

Montella, I.R., Schama, R., Valle, D., 2012. The classification of esterases: an important gene family involved in insecticide resistance - a review. Mem. Inst. Oswaldo Cruz 107, 437-449. https://doi.org/10.1590/S0074-02762012000400001.

Oswald, K.J., French, B.W., Nielson, C., Bagley, M., 2011. Selection for Cry3Bb1 resistance in a genetically diverse population of nondiapausing western corn rootworm (Coleoptera: Chrysomelidae). J. Econ. Entomol. 104, 1038-1044. https://doi.org/10. 1603/EC10312.

Pereira, A.E., Wang, H., Zukoff, S.N., Meinke, L.J., French, B.W., Siegfried, B.D., 2015 Evidence of field-evolved resistance to bifenthrin in western corn rootworm (Diabrotica virgifera virgifera LeConte) populations in western Nebraska and Kansas. PLoS One 10, e0142299. https://doi.org/10.1371/journal.pone.0142299.

Pereira, A.E., Souza, D., Zukoff, S.N., Meinke, L.J., Siegfried, B.D., 2017. Cross-resistance and synergism bioassays suggest multiple mechanisms of pyrethroid resistance in western corn rootworm populations. PLoS One 12, e0179311. https://doi.org/10. 1371/journal.pone.0179311.

Rinkevich, F.D., Su, C., Lazo, T.A., Hawthorne, D.J., Tingey, W.M., Naimov, S., Scott, J.G. 2012. Multiple evolutionary origins of knockdown resistance $(k d r)$ in pyrethroid-resistant Colorado potato beetle, Leptinotarsa decemlineata. Pestic. Biochem. Physiol. 104, 192-200. https://doi.org/10.1016/j.pestbp.2012.08.001.

Rose, R.L., Barbhaiya, L., Roe, R.M., Rock, G.C., Hodgson, E., 1995. Cytochrome P450associated insecticide resistance and the development of biochemical diagnostic assays in Heliothis virescens. Pestic. Biochem. Physiol. 51, 178-191. https://doi.org/10. 1006/pest.1995.1018.

Roush, R.T., McKenzie, J.A., 1987. Ecological genetics of insecticide and acaricide resistance. Annu. Rev. Entomol. 32, 361-380. https://doi.org/10.1146/annurev.en.32. 010187.002045 .

Russell, R.M., Robertson, J.L., 1979. Programming probit analysis. Bull. Entomol. Soc Am. 25, 191-193. https://doi.org/10.1093/besa/25.3.191.

Schilder, R.J., Zera, A.J., Black, C., Hoidal, M., Wehrkamp, C., 2011. The biochemical basis of life history adaptation: molecular and enzymological causes of NADP (+)-isocitrate dehydrogenase activity differences between morphs of Gryllus firmus that differ in lipid biosynthesis and life history. Mol. Biol. Evol. 28, 3381-3393. https://doi.org/10.1093/molbev/msr171.

Schneider, C.A., Rasband, W.S., Eliceiri, K.W., 2012. NIH image to ImageJ: 25 years of image analysis. Nat. Methods 9, 671-675. https://doi.org/10.1038/nmeth.2089.

Seong, K.M., Coates, B.S., Sun, W., Clark, J.M., Pittendrigh, B.R., 2017. Changes in neuronal signaling and cell stress response pathways are associated with a multigenic response of Drosophila melanogaster to DDT selection. Genome Biol. Evol. 9 , 3356-3372. https://doi.org/10.1093/gbe/evx252.

Shi, L., et al., 2015. Development of resistance to pyrethroid in Culex pipiens pallens population under different insecticide selection pressures. PLoS Negl. Trop. Dis. 9 (8), e0003928. https://doi.org/10.1371/journal.pntd.0003928.

Soderlund, D.M., Knipple, D.C., 2003. The molecular biology of knockdown resistance to pyrethroid insecticides. Insect Biochem. Mol. Biol. 33, 563-577. https://doi.org/10. 1016/S0965-1748(03)00023-7.

Souza, D., Peterson, J.A., Wright, R.J., Meinke, L.J., 2019. Field efficacy of soil insecticides on pyrethroid-resistant western corn rootworms (Diabrotica virgifera virgifera LeConte). Pest Manag. Sci. 76 (2), 827-833. https://doi.org/10.1002/ps.5586.

Souza, D., Vieira, B.C., Fritz, B.K., Hoffmann, W.C., Peterson, J.A., Kruger, G.R., Meinke, L.J., 2019b. Western corn rootworm pyrethroid resistance confirmed by aerial application simulations of commercial insecticides. Sci. Rep. 9, 6713. https://doi.org/ 10.1038/s41598-019-43202-w.

Stitt, M., Gibon, Y., 2014. Why measure enzyme activities in the era of systems biology? Trends Plant Sci. 19, 256-265. https://doi.org/10.1016/j.tplants.2013.11.003.

Tabashnik, B.E., 1992. Resistance risk assessment: realized heritability of resistance to Bacillus thuringiensis in diamondback moth (Lepidoptera: Plutellidae), tobacco budworm (Lepidoptera: Noctuidae), and Colorado potato beetle (Coleoptera: Chrysomelidae). J. Econ. Entomol. 85, 1551-1559. https://doi.org/10.1093/jee/85. 5.1551 .

Thangthaeng, N., Sumien, N., Forster, M.J., Shah, R.A., Yan, L.-J., 2011. Nongradient blue native gel analysis of serum proteins and in-gel detection of serum esterase activities. J. Chromatogr. B 879, 386-394. https://doi.org/10.1016/j.jchromb.2010.12.026.

Untergasser, A., Cutcutache, I., Koressaar, T., Ye, J., Faircloth, B.C., Remm, M., Rozen, S.G., 2012. Primer3-new capabilities and interfaces. Nucleic Acids Res. 40, e115. https://doi.org/10.1093/nar/gks596.

Usherwood, P.N.R., Davies, T.G.E., Mellor, I.R., O’Reilly, A.O., Peng, F., Vais, H., Khambay, B.P.S., Field, L.M., Williamson, M.S., 2007. Mutations in DIIS5 and the DIIS4-S5 linker of Drosophila melanogaster sodium channel define binding domains for pyrethroids and DDT. FEBS Lett. 581, 5485-5492. https://doi.org/10.1016/j. febslet.2007.10.057.

Wangila, D.S., Gassmann, A.J., Petzold-Maxwell, J.L., French, B.W., Meinke, L.J., 2015. Susceptibility of Nebraska western corn rootworm (Coleoptera: Chrysomelidae) populations to Bt corn events. J. Econ. Entomol. 108, 742-751. https://doi.org/10. 1093/jee/tou063.

Williamson, M.S., Denholm, I., Bell, C.A., Devonshire, A.L., 1993. Knockdown resistance $(k d r)$ to DDT and pyrethroid insecticides maps to a sodium channel gene locus in the housefly (Musca domestica). Mol. Gen. Genet. 240, 17-22. https://doi.org/10.1007/ BF00276878.

Williamson, M.S., Martinez-Torres, D., Hick, C.A., Devonshire, A.L., 1996. Identification 
of mutations in the houseflypara-type sodium channel gene associated with knockdown resistance (kdr) to pyrethroid insecticides. Mol. Gen. Genet. 252, 51-60. https://doi.org/10.1007/BF02173204.

Wing, K.D., Sacher, M., Kagaya, Y., Tsurubuchi, Y., Mulderig, L., Connair, M., Schnee, M., 2000. Bioactivation and mode of action of the oxadiazine indoxacarb in insects. In: Crop Protection, XIVth International Plant Protection Congress. vol. 19. pp. 537-545. https://doi.org/10.1016/S0261-2194(00)00070-3.

Wright, R.J., Scharf, M.E., Meinke, L.J., Zhou, X., Siegfried, B.D., Chandler, L.D., 2000. Larval susceptibility of an insecticide-resistant western corn rootworm (Coleoptera: Chrysomelidae) population to soil insecticides: laboratory bioassays, assays of detoxification enzymes, and field performance. J. Econ. Entomol. 93, 7-13. https://doi. org/10.1603/0022-0493-93.1.7.

Yang, T., Liu, N., 2011. Genome analysis of cytochrome P450s and their expression profiles in insecticide resistant mosquitoes, Culex quinquefasciatus. PLoS One 6, e29418. https://doi.org/10.1371/journal.pone.0029418.

Yang, Y., Wu, Y., Chen, S., Devine, G.J., Denholm, I., Jewess, P., Moores, G.D., 2004. The involvement of microsomal oxidases in pyrethroid resistance in Helicoverpa armigera from Asia. Insect Biochem. Mol. Biol. 34, 763-773. https://doi.org/10.1016/j.ibmb. 2004.04.001.

Yang, Y., Chen, S., Wu, S., Yue, L., Wu, Y., 2006. Constitutive overexpression of multiple cytochrome P450 genes associated with pyrethroid resistance in Helicoverpa armigera. J. Econ. Entomol. 99, 1784-1789. https://doi.org/10.1093/jee/99.5.1784.

Yu, S.J., Nguyen, S.N., 1998. Purification and characterization of carboxylamidase from the fall armyworm, Spodoptera frugiperda (J. E. Smith). Pestic. Biochem. Physiol. 60, 49-58. https://doi.org/10.1006/pest.1998.2322. 